\title{
Long-term neurocognitive dysfunction in offspring via NGF/ ERK/CREB signaling pathway caused by ketamine exposure during the second trimester of pregnancy in rats
}

\author{
Yanan $\mathrm{Li}^{1}$, Xinran $\mathrm{Li}^{1}$, Cen Guo ${ }^{1}$, Lina $\mathrm{Li}^{1}$, Yuxin Wang ${ }^{1}$, Yiming Zhang ${ }^{1}$, Yu Chen ${ }^{1}$, \\ Wenhan Liu ${ }^{1}$, Li Gao ${ }^{1}$ \\ ${ }^{1}$ College of Veterinary Medicine, Northeast Agricultural University, Harbin 150030, China
}

Correspondence to: Li Gao, email: gaoli43450@163.com

Keywords: ketamine, pregnancy, long-term neurocognitive dysfunction, ERK, synapse

Received: January 16, 2017 Accepted: March 01, 2017 Published: March 09, 2017

Copyright: Li et al. This is an open-access article distributed under the terms of the Creative Commons Attribution License (CC-BY), which permits unrestricted use, distribution, and reproduction in any medium, provided the original author and source are credited.

\section{ABSTRACT}

Early life exposure to ketamine caused neurohistopathologic changes and persistent cognitive dysfunction. For this study, a pregnant rat model was developed to investigate neurocognitive effects in the offspring, following ketamine exposure during the second trimester. Pregnant rats on gestational day 14 (equal to midtrimester pregnancy in humans), intravenously received $200 \mathrm{mg} / \mathrm{kg}$ ketamine for $3 \mathrm{~h}$. Their behavior was tested (Morris water maze, odor recognition test, and fear conditioning) at postnatal days (P25-30). Furthermore, hippocampal morphology of the offspring (P30) was examined via Nissl staining and hippocampal dendritic spine density was determined via Golgi staining. The hippocampal protein levels of nerve growth factor (NGF), extracellular signal-regulated kinase (ERK), phosphorylated-ERK (p-ERK), cyclic adenosine monophosphate response element-binding (CREB), p-CREB, synaptophysin (SYP), synapsin (SYN), and postsynaptic density-95 (PSD95) were measured via western blot. Additionally, SCH772984 (an ERK inhibitor) was used to evaluate both role and underlying mechanism of the ERK pathway in PC12 cells. We found that ketamine caused long-term neurocognitive dysfunction, reduced the density of the dendritic spin, caused neuronal loss, and down-regulated the expression of NGF, ERK, p-ERK, mitogen, and stress-activated protein kinase (MSK), CREB, P-CREB, SYP, SYN, and PSD95 in the hippocampus. These results suggest that ketamine induced maternal anesthesia during period of the fetal brain development can cause long-term neurocognitive dysfunction in the offspring, which likely happens via inhibition of the NGF-ERK-CREB pathway in the hippocampus. Our results highlight the central role of ERK in neurocognition.

\section{INTRODUCTION}

A large number of pregnant women are exposed to various types of anesthetics for surgery or diagnosis every year. Furthermore, some pregnant women will also accept surgery unrelated to childbirth during pregnancy. Published evidence links early exposure to anesthesia and cognitive impairment in the offspring [1,2]. For example, exposure to isoflurane during pregnancy can impair postnatal spatial memory and learning in the offspring [3]. Moreover, neonatal administration of commonly used anesthetic agents has been shown to induce long-term neurocognitive dysfunction in rodents [4]. Ketamine is one of the most commonly used drugs in pediatric clinical anesthesia. Its influence on learning and memory has always been of clinical concern. Ketamine is frequently consumed by drug addicts in the public, sadly including pregnant women [5]. It has been reported that ketamine had neurotoxic effects on brain development in rodents and even in primates, which persist into adulthood [6]. Ketamine may interfere with hippocampal neurogenesis and long-term neurocognitive function in rats up to seven days after birth [7]. These findings raise concerns about the potential adverse effects of ketamine exposure for fetuses and infants.

It is well known that the hippocampus plays a central role in processes of learning and memory [8], and it is therefore a common target for drug regulation. Synaptic plasticity refers to the change of neurotransmitter 
transmissions between two neurons or synapses and this is often accompanied by changes in synaptic morphology and function [9]. It is generally accepted that the hippocampal neuron synapses are associated with learning and memory [10]. Furthermore, synaptic plasticity has been suggested as the main cellular mechanism of memory [11], including synaptic formation and changes in synaptic associated protein [12]. Analysis of the synapse associated protein was coupled with that of synaptic markers such as synaptophysin (SYP), synapsin (SYN), and postsynaptic density-95 (PSD95). Among these, SYP and SYN are major integral proteins of synaptic vesicles, and their reduction has been associated with a decrease in synaptic density [13]; furthermore, PSD95 is used as a marker of dendrite branching and remodeling [14]. In addition, the nerve growth factor (NGF) plays a central role in promoting neurite outgrowth, thus enhancing memory formation in the hippocampus [15]. Chronic intracerebroventricular injection of NGF has been shown to increase the number of synapses in the hippocampus of rats, via up-regulation of SYP expression, leading to enhanced cognitive function [16]. Extracellular signal-regulated kinase (ERK) is a member of the mitogen-activated protein kinase (MAPK) pathway. ERK signaling is also involved in gene transcription, and it can induce and maintain memory [17]. Mitogen and stress-activated protein kinase (MSK) is a potent cyclic-AMP response element binding protein (CREB) kinase and phosphorylated CREB can initiate transcription of its target genes. Furthermore, CREB, the downstream regulator of the ERK cascade, has also been reported to be involved in the development of learning and memory and it has been described as an essential factor for increasing the number of synapses [18]. The activation of the ERK-CREB signaling pathway may improve spatial learning and memory [19]. These findings suggest that the proteins mentioned above are closely related to long-term neurocognition.

However, most of the existing studies in this area have focused on babies rather than offspring and the underlying mechanism remain unclear. Although ketamine is rarely administered to pregnant women in the developed countries, it is still often used as a "rescue" anesthetic when local anesthesia cannot meet normal surgical requirements in developing countries [20]. Therefore, it is important to reveal whether ketamine use during surgery or ketamine abuse during pregnancy poses a risk to unborn babies. The present study used a pregnant rat model and ketamine was injected into pregnant rats after 14 days of gestation (G14). We evaluated the capacity of learning and memory with behavioral tests (Morris water maze, odor recognition test, and fear conditioning), Nissl staining, and Golgi staining. The hippocampal protein level of NGF, ERK, p-ERK, CREB, p-CREB, SYP, SYN, and PSD95 were measured via western blot. Furthermore, in vitro cultured PC12 cells were used to validate the results. The aim of our study was to investigate the effects of ketamine exposure during the second trimester on neurocognition of the offspring.

\section{RESULTS}

\section{Physiologic response to ketamine infusion}

All anesthetized dams recovered fully without any complications. The recovery time from anesthesia was $36 \pm 3 \mathrm{~min}$. Maternal blood gas, blood glucose, and body temperature measurements were within the normal physiological range compared with control rats (Table 1). The pups weight was $83 \pm 5 \mathrm{~g}$. Two offspring had extremely low body weight (38 g and $45 \mathrm{~g}$ ) and were excluded from further studies.

\section{Hippocampal-dependent learning and memory of offspring after ketamine exposure}

\section{Morris water maze task}

The effects of ketamine exposure on spatial learning and memory in rats are shown in Figure 1. The Morris water maze test data in Figure 1A showed no significant differences in escape latencies between $\mathrm{C}$ group and $\mathrm{K}$ group during test days $1-3$. However, on the third and forth day, escape latencies of the $\mathrm{K}$ group were significantly longer compared to $\mathrm{C}$ group $(p<0.05)$. On the fifth day, the data showed that the effect of ketamine exposure on the escape latency did not significantly differ between both groups. This suggested that both groups of rats were successfully trained after all. In the spatial probe test data, as shown in Figure 1B and Figure 1C, the number of platform crossings and the time of entries into the quadrant zone were shorter in $\mathrm{K}$ groups compared to $\mathrm{C}$ group. These findings indicate that ketamine-treated rats have a weaker spatial memory than control rats. Ketamine may thus impair spatial learning and memory ability of new-born rats.

\section{Odor recognition test}

All rats in our experiments had never before been exposed to the utilized compounds and did not show a preference for either of both odors at the concentrations used in this study. During the acquisition test (as shown in Figure 3B), the animals spent considerable time investigating each of the two odorized holes and no significant difference could be detected between groups. The data of the recall test showed that the rats spent almost the same amount of time exploring each hole, indicating that they no longer remembered the odor presented during the acquisition test and thus, both odors were considered as unfamiliar in the recall test. Therefore, these findings indicate that ketamine had little effect on olfactory memory. 
Table 1: Blood gases, glucose and temperature measurements in age-matched pregnant and unpregnant rats during ketamine administration

\begin{tabular}{ccc}
\hline Arterial blood gas & Unpregnancy & Pregnancy \\
\hline Temperature $\left({ }^{\circ} \mathrm{C}\right)$ & $36.89 \pm 0.35$ & $37.11 \pm 0.50$ \\
$\mathrm{PaO} 2(\mathrm{~mm} \mathrm{Hg})$ & $103.73 \pm 3.08$ & $104.17 \pm 3.44$ \\
$\mathrm{PaCO} 2(\mathrm{~mm} \mathrm{Hg})$ & $39.54 \pm 1.56$ & $42.98 \pm 2.92$ \\
$\mathrm{HCO}-$ & $23.90 \pm 1.23$ & $24.60 \pm 1.71$ \\
$\mathrm{pH}$ & $7.18 \pm 0.01$ & $7.23 \pm 0.02$ \\
Glucose $(\mathrm{mg} / \mathrm{dl})$ & $103.73 \pm 1.76$ & $107.97 \pm 2.69$ \\
\hline
\end{tabular}

Arterial blood samples were sampled from the left cardiac ventricle immediately at the end of the $3 \mathrm{~h}$ ketamine administration. All measurements were within the normal physiological ranges and no statistical significance was found between the two groups. Data are presented as mean \pm S.E.M. $(n=3)$.
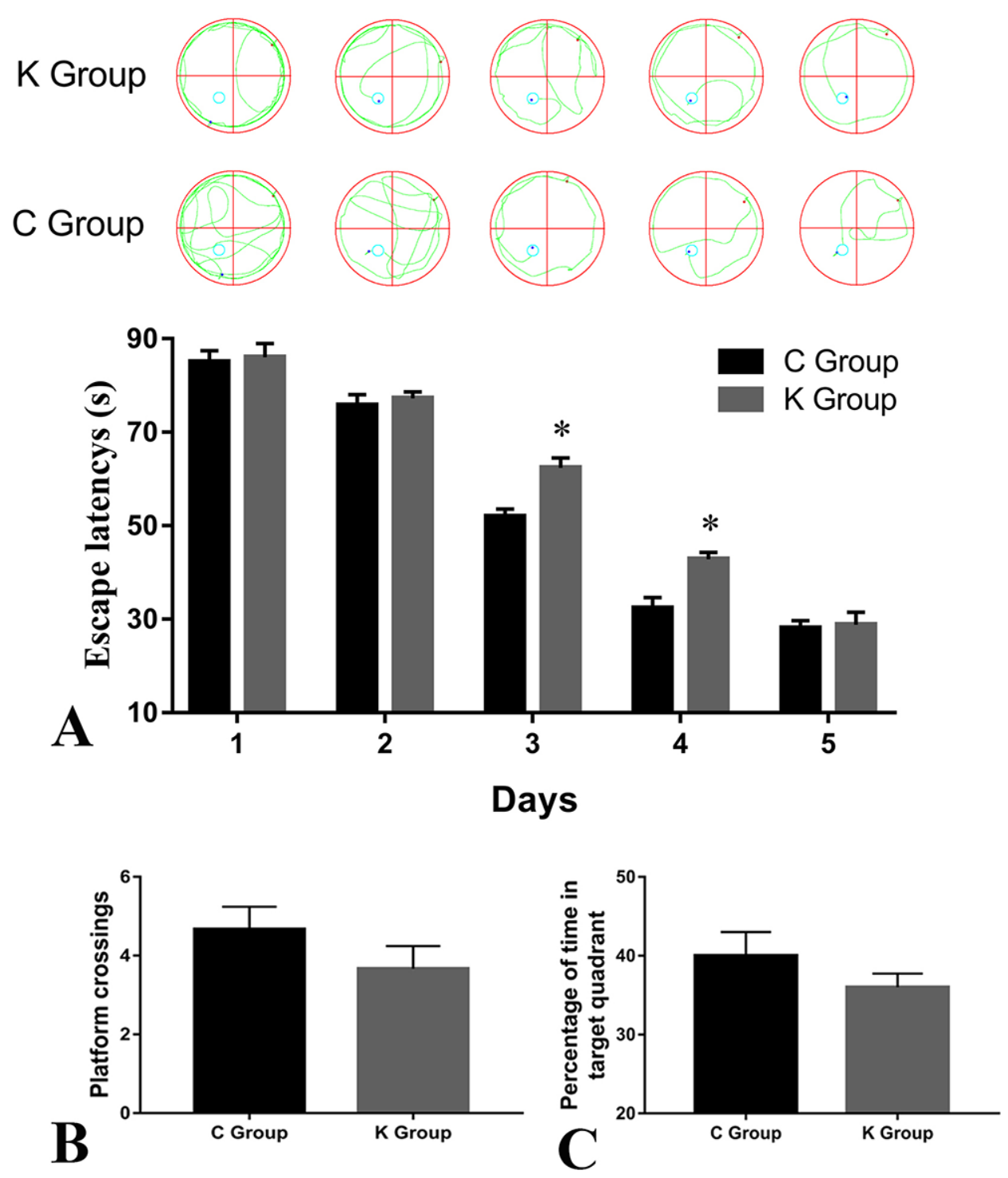

Figure 1: Morris water maze task. Anesthesia-induced spatial cognitive changes in postnatal day 30 rats. Representative swimming paths of rats are shown above the A (A) Escape latency was significantly longer in the $\mathrm{K}$ group compared to the $\mathrm{C}$ group. (B) The number of platform crossings did not significantly differ between $\mathrm{K}$ and $\mathrm{C}$ groups. (C) The percentage of time in target quadrant did not significantly differ between $\mathrm{K}$ and $\mathrm{C}$ groups. ${ }^{*} p<0.05 n=15$. 


\section{Fear conditioning}

In both context test and pre-CS test, the percentage of freezing time between both groups was not significantly different (Figure 4D). While there were significant differences $(p<0.05)$ between both groups in the CS test, the percentage of freezing time was higher in $\mathrm{C}$ group than in K group (Figure 4D). This indicates that ketamine affects learn and memory of rats under conditioning stimuli.

\section{Ketamine induced neuronal cell loss in the hippocampal CA1 and $\mathrm{CA} 3$ region of offspring}

The hippocampus is highly connected to learning and memory as well as mood associated behaviors [21]. Nissl staining was used to distinguish viable neurons from apoptotic or neurotic neurons. The former exhibited abundant cytoplasm and Nissl substance (stained as dark blue), apparent oval nuclei (stained as light blue), and prominent nucleoli, while apoptotic or necrotic cells exhibited pyknotic morphology with amorphous or fragmented nuclei. Significant differences $(p<0.05)$ were detected in cell density in the $\mathrm{CA} 1$ and $\mathrm{CA} 3$ region between $\mathrm{C}$ group and $\mathrm{K}$ group (Figure 2).

\section{Ketamine decreases dendritic spine density in offspring}

Fully impregnated CA1 and CA3 pyramidal cells were detected under Golgi staining, and the spines of the apical and basal dendrites (Figure 3A-3D) were analyzed under a light microscope with $100 \times$ oil immersion objective lens. Merely the density of the dendritic spine was determined in our study, as the different types of spines were not always clearly distinguishable (e.g., thin, mushroom, or branched dendrites). The spine density of $\mathrm{K}$ group was significantly decreased compared to that of C group $(p<0.05)$.

\section{Ketamine exposure affects synaptic protein expression}

Three synaptic proteins in hippocampal specimens were visualized via SDS-PAGE and immunoblotting with corresponding antibodies for SYP, SYN, and PSD95. For proteins of hippocampal tissue, we found significantly decreased expressions of SYP, SYN, and PSD95 in K group relative to $\mathrm{C}$ group ( $p<0.05$, Figure $4 \mathrm{G}, 4 \mathrm{H}, 4 \mathrm{I})$. Furthermore, we found the same trend in four cell groups (Figure 5G, 5H, 5I).

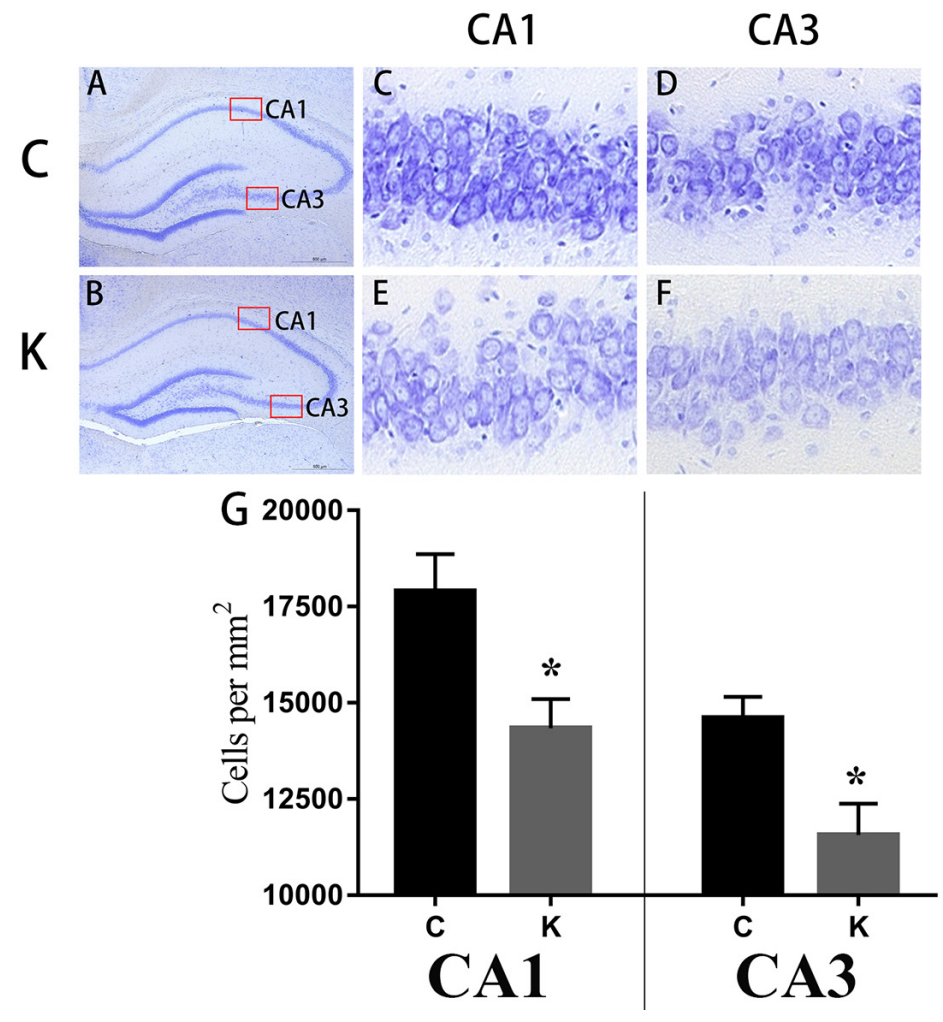

Figure 2: Nissl staining. Ketamine administered during the second trimester induced neuronal cell loss in the hippocampal CA1 and CA3 regions of offspring. Coronal sections of the dorsal hippocampus from six animals were randomly selected from each group $(n=3 /$ group) at postnatal day 30 (after behavioral tests) for Nissl-staining. Gross architecture of the hippocampus in the control and ketamine treated offspring at day 30 (A and $\mathbf{B}$, respectively), the cellular layer in the CA1 and CA3 region of hippocampi of control and ketamine treated offspring at day $30(\mathbf{C}-\mathbf{F})$, from which cell densities were calculated. Significant differences were found in cell density in CA1 and CA3 between both groups. ${ }^{*} p<0.05$. 


\section{Ketamine perturbed NGF protein and down-regulated ERK and CREB and their phosphorylation}

Ketamine injection significantly reduced the levels of the ERK, p-ERK, MSK, CREB, p-CREB, and NGF proteins in the hippocampus compared to $C$ group $(p<0.05$, Figure $4 \mathrm{~A}-4 \mathrm{~F})$. In vitro experiments using PC12 cells revealed an identical trend between $\mathrm{C}$ and $\mathrm{K}$ groups. In $\mathrm{S}$ group, the levels of these proteins were also significantly decreased ( $p<0.05$, Figure 5B-5F), except for ERK (Figure 5A).

\section{DISCUSSION}

In this study, we found that the use of ketamine in pregnant rats at G14 might possibly affect both learning and memory of space and condition. The behavioral results were verified via Nissl and Golgi stainings. It has been reported that activation of the ERK-CREB signaling pathway may improve spatial learning and memory [19]. Therefore, we selected the area upstream and downstream of the key proteins of this pathway to measure expression levels using western blots. The results showed that the contents of NGF, ERK, CREB, and SYN were decreased. In this experiment, ketamine was shown to lead to changes in oxygen concentration, blood flow, and oxygen saturation. To exclude the effects of these factors, we cultured PC12 cells in vitro and added an inhibitor, thus validating the results of in vivo experiments. Two important aspects of neurocognitive function are learning and memory. Therefore, we speculate that the changes of ERK signaling pathway can affect the neurocognitive function.

Anesthesia is widely and increasingly used in the developing brain, making it a major health issue of vital interest. This has become a greater concern with the evidence that anesthesia and surgery may cause neurodevelopmental disorders in children, while anesthetics are neurotoxic in young animals [22]. Recent studies suggested an association between anesthesia/surgery and neurocognitive impairment, and Sanders et al. suggested a causal relationship between anesthesia and neonatal brain injury [23]. However, the effects of anesthesia on the development of fetal brains, affecting postnatal memory and learning ability is controversial; studies reporting a lack of effects [24] and studies reporting permanent impairment [25] can all be found. However, these discrepancies may be due to differences in experimental methods, animals, drugs, and anesthetic durations. In fact, all general anesthetics pass the placental barrier and convincing evidence suggests that anesthetics, including ketamine, can potentially cause neuronal apoptosis in synaptogenesis as well as behavioral deficits in later life $[26,27]$. According to behavioral test results, ketaminetreated rats have weaker spatial memory as manifested by

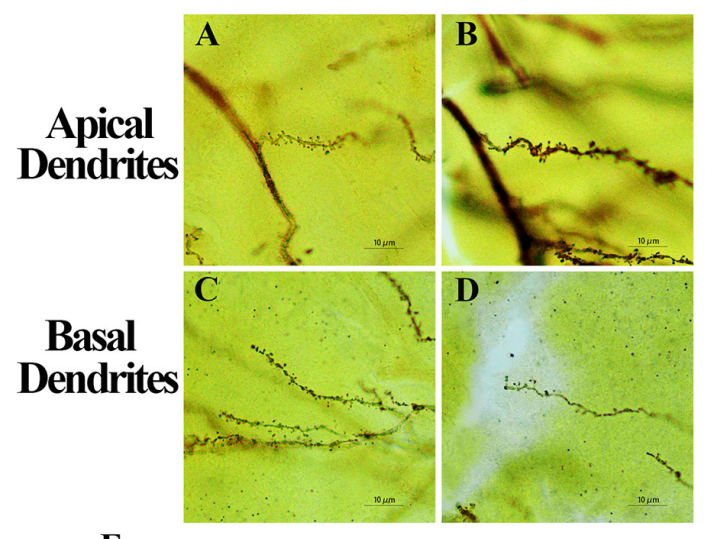

$\mathbf{E}$

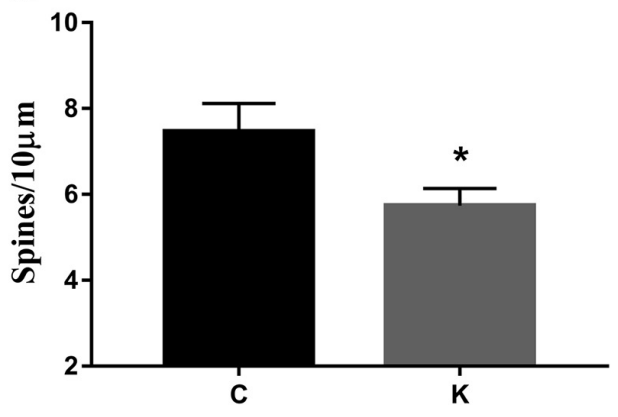

Figure 3: Golgi staining. Ketamine decreased the spinal density of pyramidal neurons from the hippocampus. Ten apical and basal dendritic sections were measured from each rat ( 5 rats/group). Analysis revealed that ketamine treatment induced a significant reduction in spinal density. (A-D) Representative spinal morphology of the hippocampus in two groups. The histogram shows mean $\pm \mathrm{SEM}$ of the dendritic spine numbers per $10 \mu \mathrm{m}$ of dendrite length. (E) There were significant differences between $\mathrm{K}$ and $\mathrm{C}$ groups. ${ }^{*} p<0.05$. 


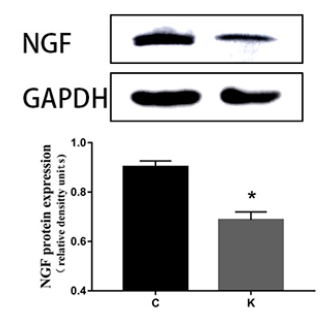

A

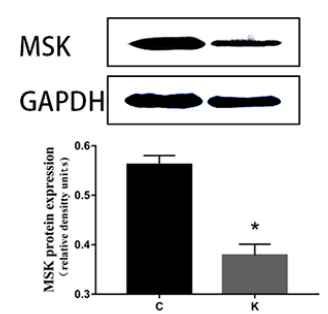

F

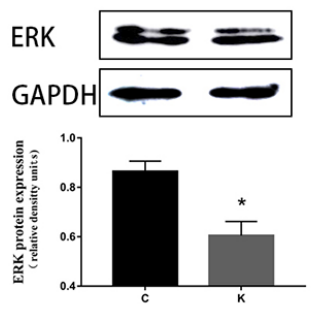

B

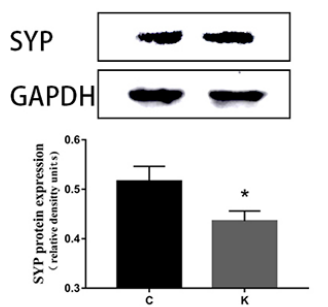

G

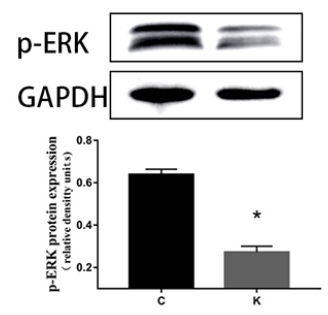

C

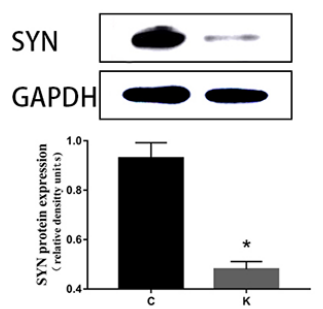

H

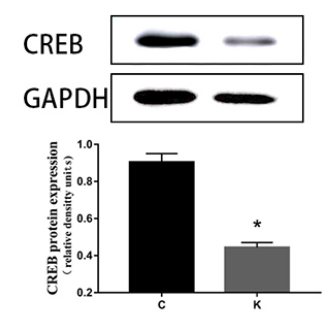

D

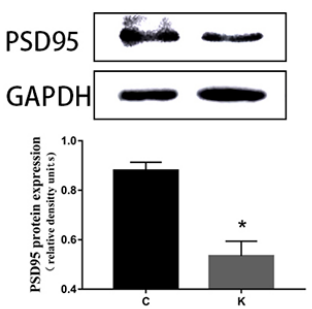

I

Figure 4: Western blot in vivo experiments. Ketamine administered during the second trimester perturbed NGF and down-regulated ERK, p-ERK, MSK, CREB, p-CREB, SYP, SYN, and PSD95 in the hippocampi of offspring. On postnatal day 30, after behavioral tests, brains were harvested for western blot analyses to determine the expression of NGF, ERK, p-ERK, MSK, CREB, p-CREB, SYP, SYN, and PSD95. (A-I) Above are representative immunoblots for the expression levels of the corresponding proteins, and below are the histograms of the quantification of the corresponding proteins normalized to GAPDH. Data are expressed as mean percentage \pm SEM of control mean values. ${ }^{*} p<0.05$.
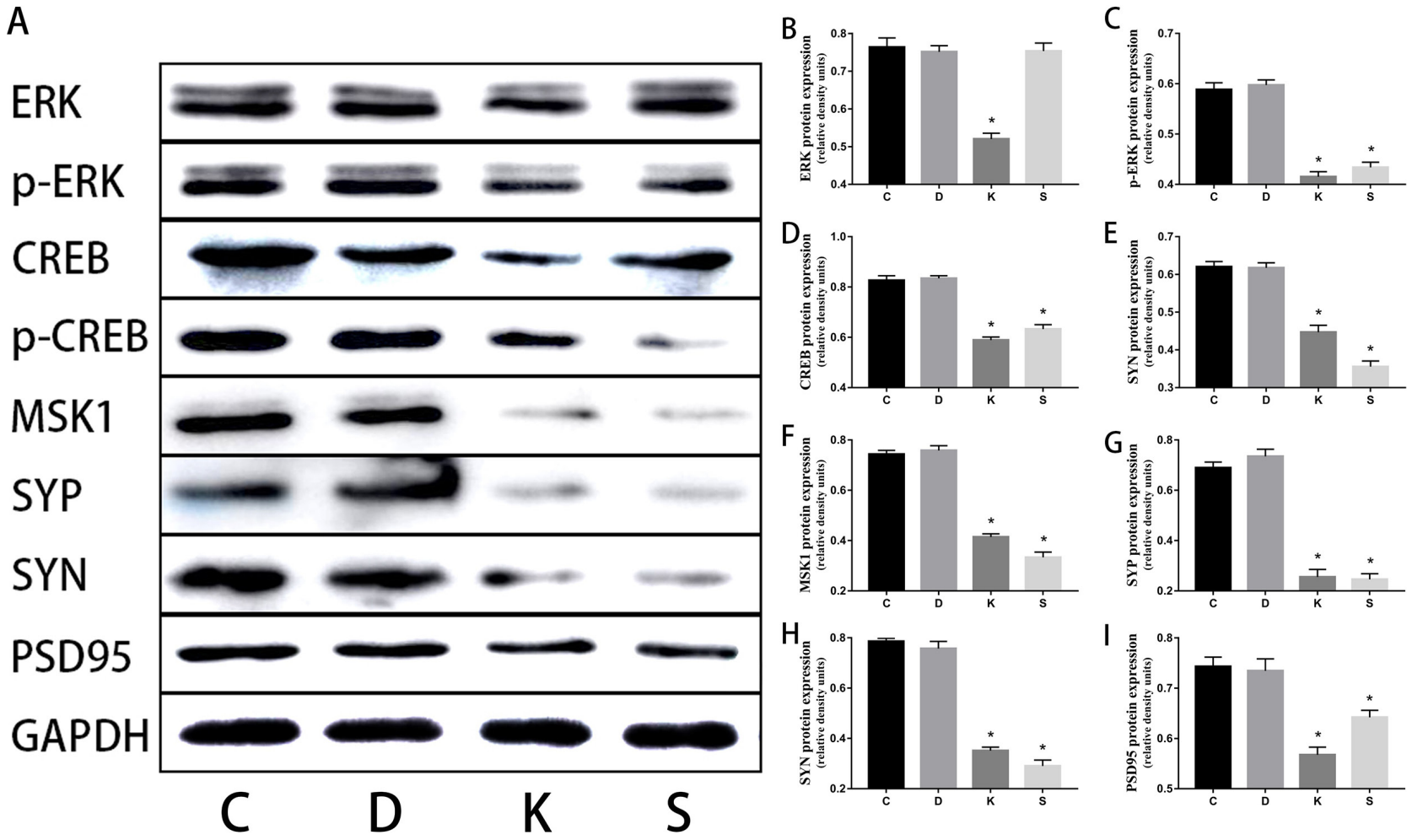

Figure 5: Western blot in vitro experiment. Ketamine administered during the second trimester down-regulated ERK, p-ERK, MSK, CREB, p-CREB, SYP, SYN, and PSD95 in PC12 cells during in vitro experiments. SCH772984 is the inhibitor of the ERK protein. Through the contrast between S group and C group, a very good effect of the inhibitor is revealed. (A) Representative immunoblots for expression levels of the corresponding proteins. (B-I) Histograms that quantify the corresponding proteins normalized to GAPDH, in which the data are expressed as mean percentages \pm SEM of control mean values. ${ }^{*} p<0.05$ 
increased latency during the Morris water maze test and conditional in the CS test; thus revealing that ketamine exposure can affect the learning and memory abilities of rat offspring, which is consistent with previous studies [27]. These findings clearly demonstrate that ketamine can cause neurocognitive functional impairment in offspring. These behavioral changes are unlikely associated with an indirect adverse effect of ketamine on pregnancy, as maternal physiological parameters during ketamine anesthesia were normal (Table 1). This further suggests that the offspring brain suffered from impaired via ketamine exposure. Moreover, under the conditions of this experiment, there were impairments of hippocampaldependent learning and memory after ketamine exposure in the offspring. This suggestion is consistent with that of Peng et al. who suggested that ketamine impairs learning and memory ability possibly via inhibition of the ERK signal transduction pathway [28].

ERK is an important serine/threonine protein kinase, which is activated via phosphorylation on Thr202 and Tyr204 [29]. Its substrate includes histones, transcription factors, and other important intracellular kinases; substances which are important components of the cell, and play a central role in the formation of learning and memory. Once activated, ERK translocated from the cytoplasm to the nucleus, where it activated specific transcription factors that in turn induce gene expression. ERKs can activate MSK [30] and activated ERK can in turn activate CREB through MSK activation. ERK can directly phosphorylate the transcription factor CREB. Montarolo et al. reported for the first time the long-term effects of cAMP-CREB pathway facilitation activities in the memory process of Aplysia, and the authors introduced the first mechanism of learning and memory dependent gene expression [31]. There is considerable body of evidence to show that activation of ERK (p-ERK) in the hippocampus enhances memory via phosphorylation of the downstream transcription factor CREB on Ser residue 133 [32]. Low expression of CREB can lead to significant damage to the memory $[33,34]$, while high expression of CREB can result in significant enhancement of memory and an improvement on social cognitive function [35]. Results from Figure 8 have shown that ketamine injection significantly reduced the level of the ERK, p-ERK, MSK, CREB, and p-CREB proteins in the hippocampus. These results suggest that ketamine could inhibit the activation of CREB by suppressing the ERK/MSK signaling pathway. This hypothesis was verified by in vitro cell experiments. After inhibitor addition, the related proteins were inhibited; thus illustrating the important position of ERK in the signal pathway. These results are consistent with prior reports about the key role of ERK in the control of gene regulation required for neuronal plasticity and longterm memory in the central nervous system [36]. A recent report shows that CREB mediated the transcription of SYP via combination between $\mathrm{p}-\mathrm{CREB}$ and the SYP promoter
[37]. ERK is a family member of the mitogen-activated protein kinase pathway, which is strongly associated with synaptogenesis, learning, and memory [38].

The hippocampus is one of the key brain regions for long-term memory [8]. Furthermore, learning and memory are closely related to neuronal synapses of the hippocampus [39]. The results show that both learning and memory abilities of the offspring were impaired. Learning disabilities may not only be caused by neural regeneration, neurodevelopmental abnormalities, neuron migration, and neuronal apoptosis, but also by synapses [40]. Synapses are the contact point between neurons, which are the basic structure of many brain functions, particularly the ability of learning and memory [41]. In synaptic impairment, impaired synapses and neurotransmitters may further affect cognition. In this study, we assessed the levels of SYN and SYP proteins, two known markers for the presynaptic membrane, which are involved in the final steps of exocytosis and synaptic formation in hippocampal neurons [42]. The level of the PSD95 protein was also assessed, which is a known marker of the postsynaptic membrane that is particularly abundant in the hippocampus where it aids the maturation of connections and plasticity (dendritic arborization and axonal branching) [43]. Early exposure to general anesthesia has been reported to transiently reduce the SYN level in the developing rat brain [44]. Beurel et al. demonstrated that ketamine treatment decreased the hippocampal membrane PSD95 level [45]. These results suggest that anesthesia exerts a striking influence on the level of SYN and PSD95 proteins. In this study, the level of SYN, SYP, and PSD95 proteins were decreased, which indicated synaptic damage [46]. Synaptogenesis occurs after the birth of a rodent. Synaptic proteins play an important role in synaptic formation, remodeling, and function, thus providing synaptic stability during brain development. For neuronal differentiation and migration, neuronal communication is of key importance [47]. Immature neurons cannot establish meaningful synaptic connections during the key stage of brain development and die via apoptosis [48]. Nissl bodies are characteristic neuronal structures in the cytoplasm of dendritic cells and neurons, and they have been reported to be involved in protein production and are sensitive indicators of neuronal function [47]. Our results showed ketamine induced neuronal cell loss in the hippocampal CA1 and CA3 regions of offspring, which is consistent with previously published results [49], it might be related to vascular injury in brain $[50,51]$. Furthermore, long-term neurocognitive function requires functional integrity of dendritic spines [52]. It has been reported, that sevoflurane can reduce the spinal density [53]. A recent study suggested that long-term inhalational anesthesia exposure leads to morphological changes of dendritic spines and synaptic loss [54]. In this study, our results showed decreased dendritic spine density in offspring caused by ketamine exposure. This indicated 
that synaptic function was disturbed and provided further evidence for a strong relationship between synapses and ketamine-induced neurocognitive dysfunction.

Neuronal synaptic growth requires NGF, which is a neurotrophic factor that plays a critical role in the differentiation, protection, and maintenance of cholinergic neurons [12], among which cholinergic neuronal dysfunction is associated with cognitive deficits [55]. NGF has a close relationship with the synapse, and can enhance synaptic communication, thus leading to an improvement of learning and memory [56]. Furthermore, the growth of axons and dendrites is critical for neuronal connectivity and alterations thereof, which may contribute to cognitive function [57]. Studies have demonstrated that NGF increased the levels of synaptophysin in cultured dorsal root ganglion neurons [58], thus promoting the formation of synaptic connections through the synthesis of synaptophysin [42]. It has been reported that chronic infusion of NGF can improve learning and memory functions through changes in hippocampus specific cells, including synaptogenesis and cell proliferation [16]. The NGF signaling pathway can stimulate ERK activity [16]. Then, ERK activation induces the activation of the CREB protein, stimulating CRE-dependent transcription and leading to NGF-induced improvement of learning and memory [59]. NGF induced glutamate release leads to CREB phosphorylation, which is necessary for synaptic activity and ultimately affects memory formation [60]. In this study, we found that ketamine resulted in a significant decrease in NGF, ERK, p-ERK, CREB, and p-CREB proteins in vivo. These results indicate that ketamine inhibited NGF-inducing activities, involving the phosphorylation of ERK and CREB in rats. Through the induction of NGF and inhibition of its downstream signaling, p-ERK and p-CREB, and the impaired synapse, ketamine ultimately attenuated neurocognitive function.

In summary, our results show that maternal exposure to ketamine during the second trimester of pregnancy resulted in long-term neurocognitive dysfunction of offspring rats, which was likely caused by an inhibition of the NGF-ERK-CREB pathway in the hippocampus.

\section{MATERIALS AND METHODS}

\section{Animals}

27 rats (351-387 g) were housed in polypropylene cages in a temperature and humidity chamber with a $12 \mathrm{~h}$ light/dark cycle, where rats had access to water and food ad libitum. All experimental procedures were performed according to the guidelines that have been approved by the Northeast Agricultural University, Harbin, China. All efforts were made to minimize the total number of utilized animals.

\section{Copulation}

One randomly selected male rat and two female rats were put into a cage to enable free mating. On the second day, observations were made for the occurrence of a vaginal embolus in the cage and sperms on vaginal smear. If vaginal emboli (Figure 6A) or sperms were detected via vaginal smear (Figure 6B), the female rat was considered pregnant, and this day was marked as gestational day 0 (G0).

\section{Experimental protocols}

18 dams were randomly divided into control $(n=9)$ and ketamine $(n=9)$ group. At G14 and since this time was equivalent to the second trimester of human pregnancy [61], the control group (C group) were left undisturbed in their home cages, while the ketamine group (K group) received a $200 \mathrm{mg} / \mathrm{kg}$ dose of ketamine (Gutian Pharmaceutical Co., Ltd. Fujian province, China) via continuous intravenous infusion with a pump (Sinomdt Co., Ltd, Shenzhen, China) via tail vein for 3 $\mathrm{h}$. The total volume of katamine was less than $2 \mathrm{~mL} / 100$ g. This duration of ketamine infusion induced a sedative state between light anesthesia and deep sedation, evidenced by a lack of voluntary movement, decreased muscle tone, and minimal reaction to painful stimulation; however, without compromising any cardio respiratory functions [62]. Three rats per group were used for subsequent blood gas analysis. The latter was confirmed with blood gas analysis in a separate cohort (Nova Biomedical blood gas analyser, Massachusetts, USA, see the Results section). The core body temperature was measured via rectal probe and maintained between 36.5 and $37.5^{\circ} \mathrm{C}$ via servo-controlled infrared lamp and heating pad throughout the experiments (RWD life science Co. Ltd., Shenzhen, China). At the end of these infusions, dams were returned to their home cages after the righting reflex had recovered. Dams in each group were allowed to naturally give birth. The pups were allowed to grow up with their mothers until postnatal day (P) 25 (the day of birth was designated as P0) when pups were weaned ( $n=108,9 /$ dam, P25-30) for behavioral tests. Subsequently, ex vivo brain samples were harvested at P30 for Nissl staining, Golgi staining, and western blotting ( $n=36,3 /$ dam for each examination, see below). A schematic representation of experimental protocols is shown in Figure 7.

\section{Behavioral test}

\section{Morris water maze}

To test hippocampal-dependent spatial cognition, the rats were trained in the standard Morris water maze [63]. The equipment consisted of a hidden white platform (10 $\mathrm{cm}$ in diameter and $1.5 \mathrm{~cm}$ below the water surface in the center of the SW quadrant). The morris water 
maze consisted of a black circular pool, filled with warm $\left(23-25^{\circ} \mathrm{C}\right)$, opaque water. The area of the maze was divided into four equal-sized quadrants: NE, NW, SE, and SW. Each rat was successively placed into the water of each of the four quadrants and a maximum of $90 \mathrm{~s}$ was allowed to find the platform. If rats failed to find the platform within this time limit, they were guided to it, and then stayed there for $10 \mathrm{~s}$. All trials were videotaped. Furthermore, a video track program allowed us to measure the time required to find the platform as well as other behavioral information of the spatial memory test (Coulbourn Instruments; USA). Therefore, we could use the output data for statistical analysis. On the sixth day, the platform was removed to conduct a probe trial, testing the ability of the rats to identify the specific location that previously contained the hidden platform. The rats were then allowed to explore for $90 \mathrm{~s}$ and the number and time of entries into the platform quadrant zone were recorded. All rats were dried after completing each test.

\section{Odor recognition test}

Olfaction is a highly developed sense in rodents. Olfactory discrimination tasks are excellent tests of learning and memory in rats and mice. For the present study, an odorized hole-board was designed and constructed specifically for mice [64]. This equipment had two holes (3-4 cm in diameter with a depth of 4.5$5 \mathrm{~cm}$ ). At the bottom of the holes, a polypropylene swab was embedded in a plastic mesh and covered with wood shavings and contained $20 \mu \mathrm{L}$ of diluted odors (1:10). In the acquisition test, one of these two odors (either carvone or limonene) was simultaneously present in both holes of the hole-board (Figure 8A) for a 2 min period. The recall test consisted of a second 2 min session in which one of both holes contained the previously presented odor, while the other hole contained the new odor (Figure 8A). The delay between acquisition and recall tests was $30 \mathrm{~min}$. Furthermore,

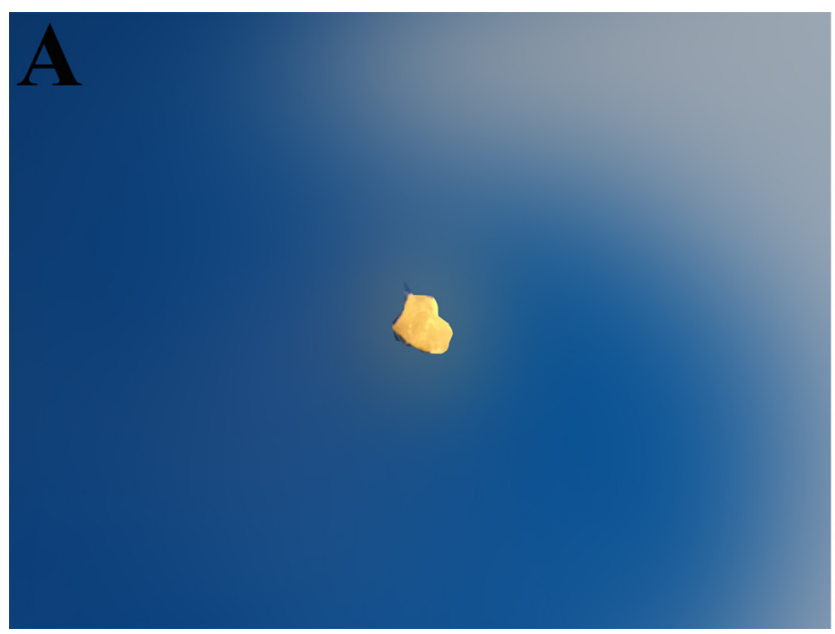

in both tests, the exploration time of rats at each hole was measured. If the rats spent less time exploring the hole containing the familiar odor than the time spent exploring the hole containing the new odor, they were considered to have remembered the familiar odor. If they take approximately the same time, this was considered to indicate that rats had forgotten the familiar odor. Both odors were alternatively used during the tests and randomly presented in each of the two holes to avoid place preference bias.

\section{Fear conditioning}

Fear conditioning is often chosen as a second independent learning and memory task that complements the Morris water task. This test consisted of three parts, training, context, and altered context test, all occurring $24 \mathrm{~h}$ apart. during training phase, rats were placed in the chamber for $3 \mathrm{~min}$ for habituation and then exposed them to a mild foot-shock paired with an auditory cue (tone, 30 s, 80 dB, $2500 \mathrm{~Hz}$; foot-shock, 2 s, 1 mA; foot-shock was delivered during the last $2 \mathrm{~s}$ of the tone presentation) (Figure 9A). A contextual test was performed in the same condition chamber for $5 \mathrm{~min}$ without any stimulation (Figure 9B) and the freezing time was recorded. An altered context test consisted of two parts, a pre-conditioningstimulus (pre-CS) test and a conditioning stimulus (CS) test. In the Pre-CS test, rats were placed into a completely altered chamber, where they remained for $3 \mathrm{~min}$. Then, during the CS test, the same training tone was delivered for further $3 \mathrm{~min}$ (Figure 9C) and the freezing time was scored. Freezing was defined as a completely immobile posture except for breathing. Therefore, associative learning and memory were assessed via length of freezing time.

\section{Nissl staining}

After the behavioral test, rats were perfused with $0.9 \%$ saline solution, followed by $4 \%$ PFA in

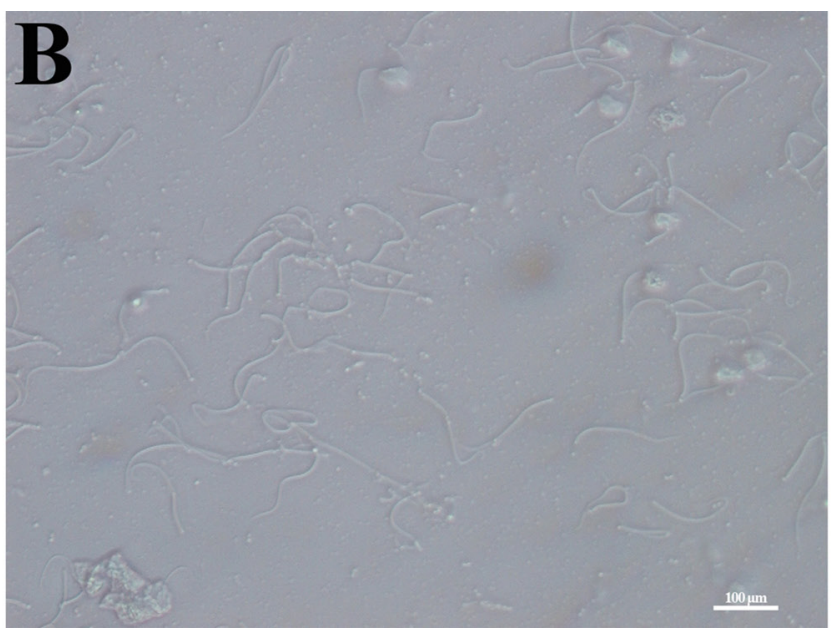

Figure 6: (A) Vaginal embolus; (B) Sperm in vaginal smear 
0.1 Mphosphate buffer at $\mathrm{pH}$ 7.4. Brains were then removed and fixed for $6-8 \mathrm{~h}$ at $4^{\circ} \mathrm{C}$. Following paraffin embedding, three coronal slices were collected from each rat, containing the dorsal hippocampus at $5 \mu \mathrm{m}$ thickness. Then, toluidine blue staining (Nissl staining) was performed. Representative photomicrographs of the pyramidal cell layer of CA1 and the CA3 region were microscopically captured. Quantitative analysis of the ratios of viable neurons was processed via Image-Pro Plus (Leica DMLB) software at $400 \times$ magnification. An average of three Nissl-stained sections was calculated to yield one single parameter per rat. All microscopic analyses were conducted by an observer blinded to the groups.

\section{Golgi staining}

Golgi staining to obtain the hippocampal dendritic spine density was conducted with the FD Rapid Golgi Stain TMKit (FDNeuro Technologies Inc., Ellicott City, MD), following the manufacturer's instructions. Coronal tissue sections of $150 \mu \mathrm{m}$ thicknesses were sliced at room temperature using a vibratome (Leica VT1200S, Germany). After slides were dehydrated with a gradient of $50 \%, 75 \%, 95 \%$, to $100 \%$ ethanol and cleared in xylene, we prepared the specimens, using slide coverslips and sealed them with Permount. The slides were then viewed in detail with a light microscope (Leica DFC420, Germany). We analyzed the stained spine, using

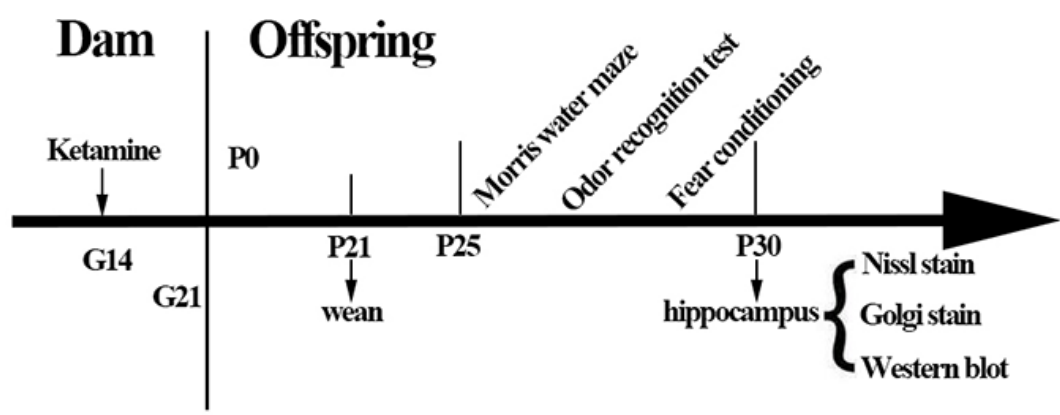

Figure 7: Flow chart of experimental protocols. $\mathrm{E}=$ gestation day; $\mathrm{P}=$ postnatal day.

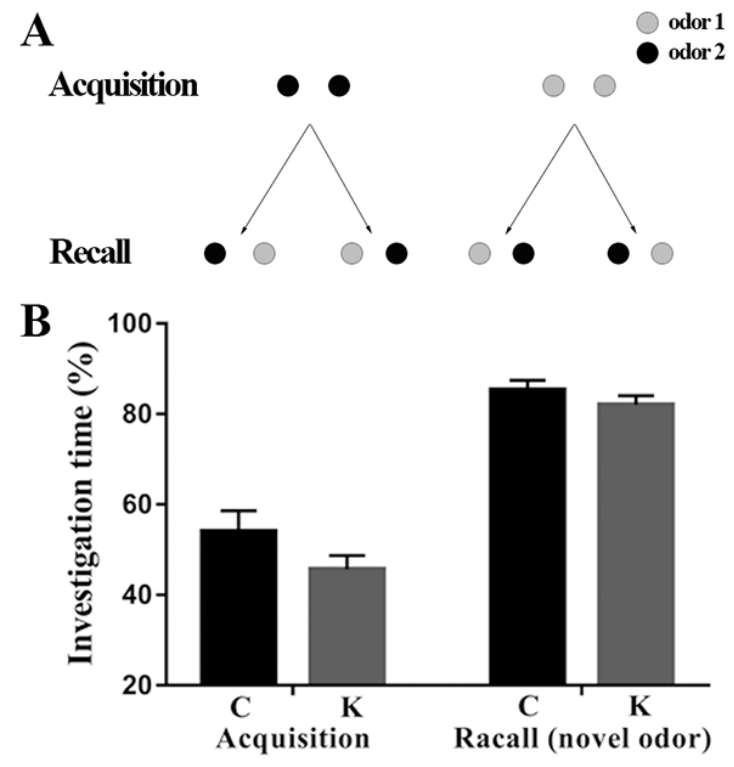

Figure 8: Odor recognition test. (A) In a first acquisition test of 2 min duration, both holes were odorized with the same compound and were equally explored by the animals. In a recall test after a delay of $30 \mathrm{~min}$, one hole was odorized with the previously presented odor during the acquisition test, while the other hole contained a new and unknown odorant compound. The placement of the familiar and new odors was randomized to avoid place preference bias. (B) Odor recognition test. Rats were subjected to the acquisition test (2 min) with either carvone or limonene present in both holes of the hole-board. The percent investigation times (vertical axis) of both holes were similar (open bars: "Acquisition," Hole 1 and Hole 2). Immediately following the acquisition test, all animals received an i.p. injection of control (physiological saline) and were submitted to the recall test after a delay of $30 \mathrm{~min}$. The bars (Recall-novel odor) represent the mean exploration time of the hole containing the new odor, expressed as the percentage of the total exploration time of both holes. At a delay of 30 minboth holes were equally explored, indicating that rats could no longer remember the familiar odor (one-sample $t$-test; $p>0.05$ ). 
techniques similar to those described in other studies [65, 66]. Six well-impregnated pyramidal neurons that were clearly distinguishable from others in each hippocampus were analyzed $(20 \times$ objective lens $)$. Five segments of 10 $\mu \mathrm{m}$ (or longer) of apical dendrites each were randomly selected from each pyramidal neuron for closer inspection (via $100 \times$ oil immersion lens) to quantify the spinal density. Spinal density of secondary apical dendrites was analyzed at proximal segments, emerging at more than $50 \mu \mathrm{m}$ from the soma of the hippocampal CA1 and CA3 neurons. All of these spines were required to have a clearly distinguishable base or origin and had to be isolated from neighboring dendrites. Spinal density was calculated per $10 \mu \mathrm{m}$ of dendritic length. The open-source ImageJ1.48 $r$ Java image-viewing and image-processing software (Wayne Rasband, NIH, USA) was utilized to calibrate the scale and enlarge the segment of the spines. All analyses were completed by an investigator blinded to experimental conditions.

\section{Cell culture and treatment}

PC12 cells were obtained from the College of Pharmacy of the Sun Yat-Sen University (Guangzhou, China). Cells were seeded in $25 \mathrm{~cm}^{2}$ flasks at a density of $1 \times 10^{5}$ cells and maintained in DMEM, supplemented with $100 \mathrm{U} / \mathrm{ml}$ penicillin (Beyotime Biotechnology), 100 $\mathrm{U} / \mathrm{ml}$ streptomycin (Beyotime Biotechnology), and 10\% fetal bovine serum (FBS, biological industries) at $37{ }^{\circ} \mathrm{C}$ in a humidified atmosphere of $95 \%$ air and $5 \% \mathrm{CO}_{2} .24$ hours prior to the start of experiments, NGF was added to induce synaptic production in PC12 cells. The cells were randomized into 4 groups: the control group (C group), the ketamine group $(0.6 \mu \mathrm{g} / \mathrm{mL}, \mathrm{K}$ group $)$, the DMSO group (D group), and the SCH772984 group (10 $\mu \mathrm{mol} / \mathrm{L}$, $\mathrm{S}$ group). The cells of these four groups were subcultured for $24 \mathrm{~h}$ in the same conditions than prior to incubation with these treatments. After $3 \mathrm{~h}$ of culture, the extracted protein was used for western blotting.

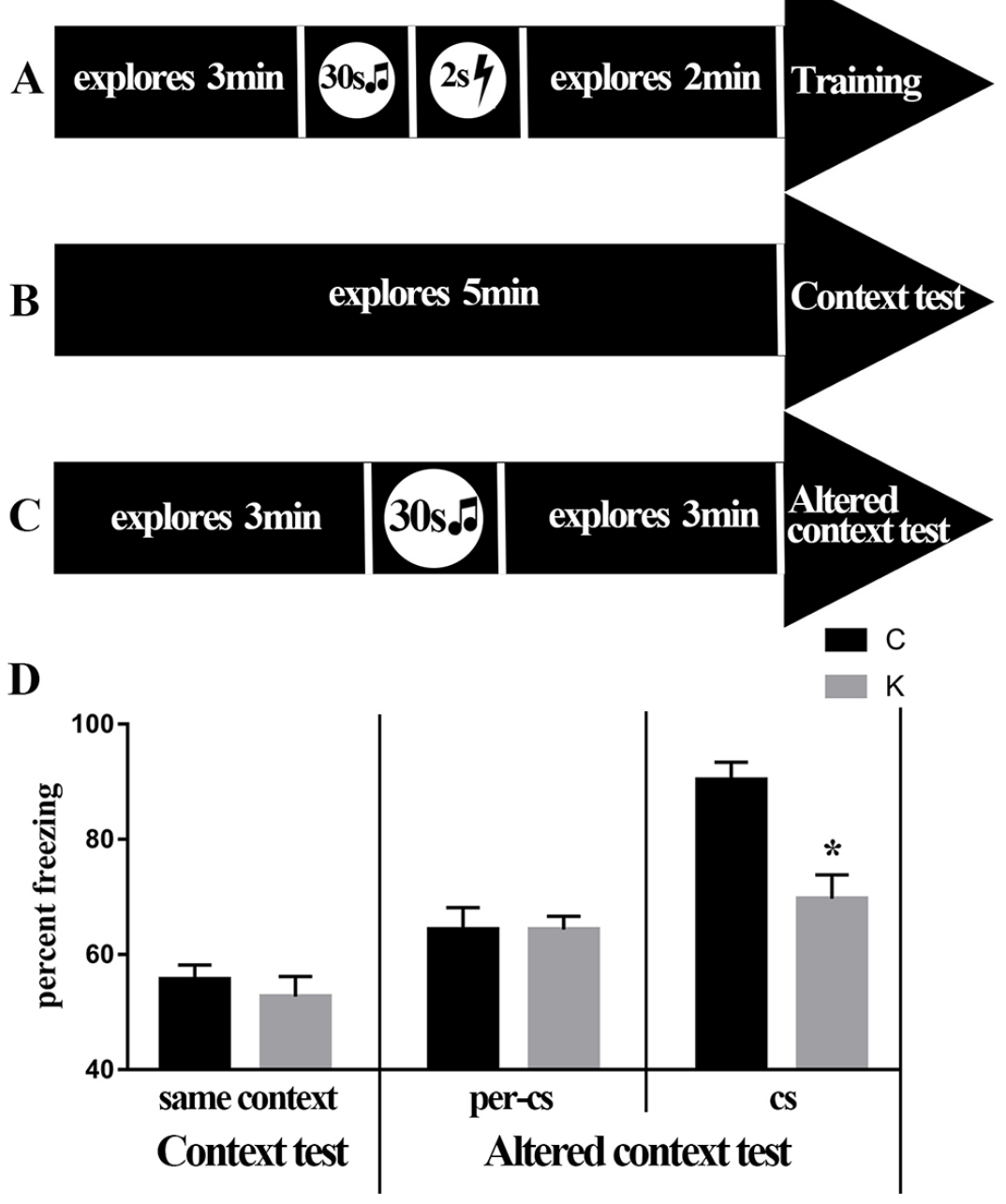

Figure 9: Fear conditioning. (A-C) Flow chart of the fear conditioning test. (D) The histogram shows that no significant difference was detected in the context test and the pre-cs test $(p>0.05)$ and a significant difference was detected in the cs test $(p<0.05)$. 


\section{Western blot}

Western blot analysis was performed as previously described [67]. In brief, neurons were harvested in a cell lysis buffer. Hippocampal fragments were isolated after behavioral test and stored in a $-80^{\circ} \mathrm{C}$ freezer until further use. At the time of processing, tissue lysis buffer (containing protease inhibitors, $50 \mathrm{mM}$ Tris$\mathrm{HCl}$, at a $\mathrm{pH}$ of 7.6) was added to the samples on ice; then, the tissue was homogenised via ultrasonification (Ningbo scientz biotechnology Co. Ltd., Ningbo, China) and centrifuged at $12000 \mathrm{~g}$ for $10 \mathrm{~min}$ at $4^{\circ} \mathrm{C}$. The protein concentration in the supernatant was measured with a BCA assay kit (Beyotime Institute of Biotechnology, China). Then, the supernatants were mixed with gel loading buffer $(50 \mathrm{mM}$ Tris- $\mathrm{HCl}, 10 \%$ SDS, $10 \%$ glycerol, $10 \%$ 2-mercaptoethanol, $2 \mathrm{mg} / \mathrm{mL}$ bromophenol blue) at a ratio of $1: 1$ and boiled for 5 min. Then, subjected to SDS-PAGE (10\% acrylamide gels for GAPDH ERK, p-ERK, CREB, p-CREB, MSK1, SYP, SYN, PSD95, and 15\% acrylamide gels for NGF, $120 \mathrm{~V}, 70 \mathrm{~min}$ ). The separated proteins were transferred onto nitrocellulose (NC) membranes and incubated with rabbit anti- GAPDH, NGF, ERK, p-ERK, CREB, p-CREB, MSK1, SYP, SYN, and PSD95 (1:600, EnoGene, Nanjing, China) overnight at a temperature of $4{ }^{\circ} \mathrm{C}$. The membrane was exposed to either rabbit or mouse secondary antibodies (1:2 000, EnoGene, Nanjing, China) for $1.5 \mathrm{~h}$ at room temperature. The blots were visualized via Scanmaker 3836 (Microtek Technology co., LTD, Shanghai, China) and quantified with the Quantity One software (Bio-Rad Laboratories, Inc., USA). Expressions of NGF, ERK, p-ERK, CREB, p-CREB, MSK1, SYP, SYN, and PSD95 were determined by calculating their density ratio to the GAPDH band, and then normalized to the control group.

\section{Statistical analysis}

All statistical parameters were calculated using the GraphPad Prism 7.0 software package. Values are expressed as the mean \pm S.D. Behavioral test, Nissl staining, Golgi staining, and Western blots in vivo were evaluated with the Student's $t$-test. Western blots in vitro were analyzed via one-way ANOVA analysis followed by Tukey's post hoc test. Differences with a $p$-value below 0.05 were considered statistically significant.

\section{Authors' contributions}

YL and LG designed the study. YZ and YW cared for animals and collected samples. YL and XL collected and analyzed data. YL, XL, YC, and WL processed brain tissue. YL, LL, and CG interpreted the data. YL wrote and edited the manuscript. All authors critically reviewed the content and approved the final version for publication.

\section{ACKNOWLEDGMENTS}

This study was supported by the National Natural Science Foundation of China (31572580 and 31372491).

\section{CONFLICTS OF INTEREST}

None.

\section{REFERENCES}

1. Wilder RT, Flick RP, Sprung J, Katusic SK, Barbaresi WJ, Mickelson C, Gleich SJ, Schroeder DR, Weaver AL, Warner DO. Early exposure to anesthesia and learning disabilities in a population-based birth cohort. Anesthesiology. 2009; 110: 796-804. doi: 10.1097/01.anes.0000344728.34332.5d.

2. Monk TG, Weldon BC, Garvan CW, Dede DE, van der Aa MT, Heilman KM, Gravenstein JS. Predictors of cognitive dysfunction after major noncardiac surgery. Anesthesiology. 2008; 108: 18-30. doi: 10.1097/01. anes.0000296071.19434.1e.

3. Kong FJ, Tang YW, Lou AF, Chen H, Xu LH, Zhang XM, Lu HS. Effects of isoflurane exposure during pregnancy on postnatal memory and learning in offspring rats. Mol Biol Rep. 2012; 39:4849-55. doi: 10.1007/s11033-011-1279-z.

4. Yon JH, Daniel-Johnson J, Carter LB, Jevtovic-Todorovic V. Anesthesia induces neuronal cell death in the developing rat brain via the intrinsic and extrinsic apoptotic pathways. Neuroscience. 2005; 135:815-27. doi: 10.1016/j. neuroscience.2005.03.064.

5. Rofael HZ, Turkall RM, Abdel-Rahman MS. Immunomodulation by cocaine and ketamine in postnatal rats. Toxicology. 2003; 188:101-14.

6. Wang SQ, Fang F, Xue ZG, Cang J, Zhang XG. Neonatal sevoflurane anesthesia induces long-term memory impairment and decreases hippocampal PSD-95 expression without neuronal loss. Eur Rev Med Pharmacol Sci. 2013; 17: 941-50.

7. Huang CC, Chou D, Yeh CM, Hsu KS. Acute food deprivation enhances fear extinction but inhibits long-term depression in the lateral amygdala via ghrelin signaling. Neuropharmacology. 2016; 101:36-45. doi: 10.1016/j. neuropharm.2015.09.018.

8. Squire LR. Memory and the hippocampus: a synthesis from findings with rats, monkeys, and humans. Psychol Rev. 1992; 99:195-231.

9. Liu H, Yang J, Liu Q, Jin C, Wu S, Lu X, Zheng L, Xi Q, Cai Y. Lanthanum chloride impairs spatial memory through ERK/MSK1 signaling pathway of hippocampus in rats. Neurochem Res. 2014; 39:2479-91. doi: 10.1007/s11064014-1452-6.

10. Carretero-Guillen A, Pacheco-Calderon R, DelgadoGarcia JM, Gruart A. Involvement of hippocampal inputs and intrinsic circuit in the acquisition of context and cues during classical conditioning in behaving rabbits. Cereb Cortex. 2015; 25:1278-89. doi: 10.1093/cercor/bht321. 
11. Lu Y, Christian K, Lu B. BDNF: a key regulator for protein synthesis-dependent LTP and long-term memory? Neurobiol Learn Mem. 2008; 89:312-23. doi: 10.1016/j. nlm.2007.08.018.

12. Kim SY, Allred RP, Adkins DL, Tennant KA, Donlan NA, Kleim JA, Jones TA. Experience with the "good" limb induces aberrant synaptic plasticity in the perilesion cortex after stroke. J Neurosci. 2015; 35:8604-10. doi: 10.1523/ JNEUROSCI.0829-15.2015.

13. Eastwood SL, Harrison PJ. Synaptic pathology in the anterior cingulate cortex in schizophrenia and mood disorders. A review and a Western blot study of synaptophysin, GAP-43 and the complexins. Brain Res Bull. 2001; 55:569-78.

14. Grillo CA, Piroli GG, Wood GE, Reznikov LR, McEwen BS, Reagan LP. Immunocytochemical analysis of synaptic proteins provides new insights into diabetes-mediated plasticity in the rat hippocampus. Neuroscience. 2005; 136:477-86. doi: 10.1016/j.neuroscience.2005.08.019.

15. Choi JG, Moon M, Jeong HU, Kim MC, Kim SY, Oh MS. Cistanches Herba enhances learning and memory by inducing nerve growth factor. Behav Brain Res. 2011; 216:652-8. doi: 10.1016/j.bbr.2010.09.008.

16. Birch AM, Kelly AM. Chronic intracerebroventricular infusion of nerve growth factor improves recognition memory in the rat. Neuropharmacology. 2013; 75:255-61. doi: 10.1016/j.neuropharm.2013.07.023.

17. Maher P, Akaishi T, Abe K. Flavonoid fisetin promotes ERK-dependent long-term potentiation and enhances memory. Proc Natl Acad Sci USA. 2006; 103:16568-73. doi: 10.1073/pnas.0607822103.

18. Tully T, Bourtchouladze R, Scott R, Tallman J. Targeting the CREB pathway for memory enhancers. Nat Rev Drug Discov. 2003; 2:267-77. doi: 10.1038/nrd1061.

19. Lei Y, Chen J, Zhang W, Fu W, Wu G, Wei H, Wang Q, Ruan J. In vivo investigation on the potential of galangin, kaempferol and myricetin for protection of D-galactoseinduced cognitive impairment. Food Chem. 2012; 135:2702-7. doi: 10.1016/j.foodchem.2012.07.043.

20. Craven R. Ketamine. Anaesthesia. 2007; 62:48-53. doi: 10.1111/j.1365-2044.2007.05298.x.

21. Femenia T, Gomez-Galan M, Lindskog M, Magara S. Dysfunctional hippocampal activity affects emotion and cognition in mood disorders. Brain Res. 2012; 1476:58-70. doi: 10.1016/j.brainres.2012.03.053.

22. Sun L. Early childhood general anaesthesia exposure and neurocognitive development. Br J Anaesth. 2010; 105:i618. doi: 10.1093/bja/aeq302.

23. Sanders RD, Hassell J, Davidson AJ, Robertson NJ, Ma D. Impact of anaesthetics and surgery on neurodevelopment: an update. Br J Anaesth. 2013; 110:i53-72. doi: 10.1093/ bja/aet054.

24. McClaine RJ, Uemura K, de la Fuente SG, Manson RJ, Booth JV, White WD, Campbell KA, McClaine DJ, Benni PB, Eubanks WS, Reynolds JD. General anesthesia improves fetal cerebral oxygenation without evidence of subsequent neuronal injury. J Cereb Blood Flow Metab. 2005; 25:1060-9. doi: 10.1038/sj.jcbfm.9600094.

25. Kong F, Xu L, He D, Zhang X, Lu H. Effects of gestational isoflurane exposure on postnatal memory and learning in rats. Eur J Pharmacol. 2011; 670:168-74. doi: 10.1016/j. ejphar.2011.08.050.

26. Brambrink AM, Evers AS, Avidan MS, Farber NB, Smith DJ, Martin LD, Dissen GA, Creeley CE, Olney JW. Ketamine-induced neuroapoptosis in the fetal and neonatal rhesus macaque brain. Anesthesiology. 2012; 116:372-84. doi: 10.1097/ALN.0b013e318242b2cd.

27. Zheng H, Dong Y, Xu Z, Crosby G, Culley DJ, Zhang Y, Xie Z. Sevoflurane anesthesia in pregnant mice induces neurotoxicity in fetal and offspring mice. Anesthesiology. 2013; 118:516-26. doi: 10.1097/ALN.0b013e3182834d5d.

28. Peng S, Zhang Y, Zhang J, Wang H, Ren B. Effect of ketamine on ERK expression in hippocampal neural cell and the ability of learning behavior in minor rats. Mol Biol Rep. 2010; 37:3137-42. doi: 10.1007/s11033-009-9892-9.

29. Kim SJ, Guerrero N, Wassef G, Xiao J, Mehta HH, Cohen $\mathrm{P}$, Yen $\mathrm{K}$. The mitochondrial-derived peptide humanin activates the ERK1/2, AKT, and STAT3 signaling pathways and has age-dependent signaling differences in the hippocampus. Oncotarget. 2016; 7:46899-912. doi: 10.18632/oncotarget.10380.

30. Brami-Cherrier K, Roze E, Girault JA, Betuing S, Caboche J. Role of the ERK/MSK1 signalling pathway in chromatin remodelling and brain responses to drugs of abuse. J Neurochem. 2009; 108:1323-35. doi: 10.1111/j.1471-4159.2009.05879.x.

31. Montarolo PG, Kandel ER, Schacher S. Long-term heterosynaptic inhibition in Aplysia. Nature. 1988; 333:171-4. doi: 10.1038/333171a0.

32. Kim SW, Ha NY, Kim KI, Park JK, Lee YH. Memoryimproving effect of formulation-MSS by activation of hippocampal MAPK/ERK signaling pathway in rats. BMB Rep. 2008; 41:242-7.

33. Sweatt JD. Mitogen-activated protein kinases in synaptic plasticity and memory. Curr Opin Neurobiol. 2004; 14:311-7. doi: 10.1016/j.conb.2004.04.001.

34. Li X, Guo C, Li Y, Li L, Wang Y, Zhang Y, Li Y, Chen Y, Liu W, Gao L. Ketamine administered pregnant rats impair learning and memory in offspring via the CREB pathway. Oncotarget. 2017 Feb 16. doi: 10.18632/oncotarget.15405. [Epub ahead of print].

35. Kida S, Josselyn SA, Pena de Ortiz S, Kogan JH, Chevere I, Masushige S, Silva AJ. CREB required for the stability of new and reactivated fear memories. Nat Neurosci. 2002; 5:348-55. doi: 10.1038/nn819.

36. Zhang F, Zhu Q, Xue Q, Luo Y, Yu B. Extra-cellular signal-regulated kinase (ERK) is inactivated associating hippocampal ARC protein up-regulation in sevoflurane induced bidirectional regulation of memory. Neurochem Res. 2013; 38:1341-7. doi: 10.1007/s11064-013-1027-y. 
37. Krasnova IN, Chiflikyan M, Justinova Z, McCoy MT, Ladenheim B, Jayanthi S, Quintero C, Brannock C, Barnes C, Adair JE, Lehrmann E, Kobeissy FH, Gold MS, et al. CREB phosphorylation regulates striatal transcriptional responses in the self-administration model of methamphetamine addiction in the rat. Neurobiol Dis. 2013; 58:132-43. doi: 10.1016/j.nbd.2013.05.009.

38. Allen KD, Gourov AV, Harte C, Gao P, Lee C, Sylvain D, Splett JM, Oxberry WC, van de Nes PS, Troy-Regier MJ, Wolk J, Alarcon JM, Hernandez AI. Nucleolar integrity is required for the maintenance of long-term synaptic plasticity. PLoS One. 2014; 9:e104364. doi: 10.1371/journal.pone.0104364.

39. Kempf SJ, Metaxas A, Ibanez-Vea M, Darvesh S, Finsen B, Larsen MR. An integrated proteomics approach shows synaptic plasticity changes in an APP/PS1 Alzheimer's mouse model. Oncotarget. 2016; 7:33627-48. doi: 10.18632/oncotarget.9092.

40. Lunardi N, Ori C, Erisir A, Jevtovic-Todorovic V. General anesthesia causes long-lasting disturbances in the ultrastructural properties of developing synapses in young rats. Neurotox Res. 2010; 17:179-88. doi: 10.1007/s12640009-9088-z.

41. Coleman P, Federoff H, Kurlan R. A focus on the synapse for neuroprotection in Alzheimer disease and other dementias. Neurology. 2004; 63:1155-62.

42. Tarsa L, Goda Y. Synaptophysin regulates activitydependent synapse formation in cultured hippocampal neurons. Proc Natl Acad Sci U S A. 2002; 99:1012-6. doi: 10.1073/pnas.022575999.

43. Ladurelle N, Gabriel C, Viggiano A, Mocaer E, Baulieu EE, Bianchi M. Agomelatine (S20098) modulates the expression of cytoskeletal microtubular proteins, synaptic markers and BDNF in the rat hippocampus, amygdala and PFC. Psychopharmacology (Berl). 2012; 221:493-509. doi: 10.1007/s00213-011-2597-5.

44. Nikizad H, Yon JH, Carter LB, Jevtovic-Todorovic V. Early exposure to general anesthesia causes significant neuronal deletion in the developing rat brain. Ann N Y Acad Sci. 2007; 1122:69-82. doi: 10.1196/annals.1403.005.

45. Beurel E, Grieco SF, Amadei C, Downey K, Jope RS. Ketamine-induced inhibition of glycogen synthase kinase-3 contributes to the augmentation of alpha-amino-3-hydroxy5-methylisoxazole-4-propionic acid (AMPA) receptor signaling. Bipolar Disord. 2016; 18:473-80. doi: 10.1111/ bdi. 12436 .

46. Tessier-Lavigne M, Goodman CS. The molecular biology of axon guidance. Science. 1996; 274:1123-33.

47. Liu J, Zhao Y, Yang J, Zhang X, Zhang W, Wang P. Neonatal Repeated Exposure to Isoflurane not Sevoflurane in Mice Reversibly Impaired Spatial Cognition at Juvenile-Age. Neurochem Res. 2016. doi: 10.1007/s11064-016-2114-7.

48. Ikonomidou C, Bittigau P, Ishimaru MJ, Wozniak DF, Koch C, Genz K, Price MT, Stefovska V, Horster F, Tenkova T, Dikranian K, Olney JW. Ethanol-induced apoptotic neurodegeneration and fetal alcohol syndrome. Science. 2000; 287:1056-60.

49. Zhao T, Li Y, Wei W, Savage S, Zhou L, Ma D. Ketamine administered to pregnant rats in the second trimester causes long-lasting behavioral disorders in offspring. Neurobiol Dis. 2014; 68:145-55. doi: 10.1016/j.nbd.2014.02.009.

50. Cao C, Fan R, Zhao J, Zhao X, Yang J, Zhang Z, Xu S. Impact of exudative diathesis induced by selenium deficiency on LncRNAs and their roles in the oxidative reduction process in broiler chick veins. Oncotarget. 2017;8:2069520705. doi: 10.18632/oncotarget.14971.

51. Cao C, Zhao X, Fan R, Zhao J, Luan Y, Zhang Z, Xu S. Dietary selenium increases the antioxidant levels and ATPase activity in the arteries and veins of poultry. Biol Trace Elem Res. 2016; 172:222-7. doi: 10.1007/s12011-015-0584-0.

52. Segal M. Dendritic spines and long-term plasticity. Nat Rev Neurosci. 2005; 6:277-84. doi: 10.1038/nrn1649.

53. Xiao H, Liu B, Chen Y, Zhang J. Learning, memory and synaptic plasticity in hippocampus in rats exposed to sevoflurane. Int J Dev Neurosci. 2016; 48:38-49. doi: 10.1016/j.ijdevneu.2015.11.001.

54. Amrock LG, Starner ML, Murphy KL, Baxter MG. Longterm effects of single or multiple neonatal sevoflurane exposures on rat hippocampal ultrastructure. Anesthesiology. 2015; 122:87-95. doi: 10.1097/ALN.0000000000000477.

55. Davies P, Maloney AJ. Selective loss of central cholinergic neurons in Alzheimer's disease. Lancet. 1976; 2:1403.

56. Schliebs R, Arendt T. The cholinergic system in aging and neuronal degeneration. Behav Brain Res. 2011; 221:555-63. doi: 10.1016/j.bbr.2010.11.058.

57. Santos NA, Martins NM, Sisti FM, Fernandes LS, Ferreira RS, de Freitas O, Santos AC. The cannabinoid betacaryophyllene (BCP) induces neuritogenesis in PC12 cells by a cannabinoid-receptor-independent mechanism. Chem Biol Interact. 2017; 261:86-95. doi: 10.1016/j.cbi.2016.11.015.

58. Takazaki R, Nishimura I, Yoshikawa K. Necdin is required for terminal differentiation and survival of primary dorsal root ganglion neurons. Exp Cell Res. 2002; 277:220-32.

59. Kim HG, Oh MS. Memory-enhancing effect of Mori Fructus via induction of nerve growth factor. Br J Nutr. 2013; 110: 86-94. doi: 10.1017/S0007114512004710.

60. Berry A, Bindocci E, Alleva E. NGF, brain and behavioral plasticity. Neural Plast. 2012; 2012:784040. doi: $10.1155 / 2012 / 784040$.

61. Clancy B, Darlington RB, Finlay BL. Translating developmental time across mammalian species. Neuroscience. 2001; 105:7-17.

62. Green CJ, Knight J, Precious S, Simpkin S. Ketamine alone and combined with diazepam or xylazine in laboratory animals: a 10 year experience. Lab Anim. 1981; 15:163-70.

63. Morris RG, Garrud P, Rawlins JN, O'Keefe J. Place navigation impaired in rats with hippocampal lesions. Nature. 1982; 297:681-3. 
64. Mandairon N, Sacquet J, Garcia S, Ravel N, Jourdan F, Didier A. Neurogenic correlates of an olfactory discrimination task in the adult olfactory bulb. Eur J Neurosci. 2006; 24: 3578-88. doi: 10.1111/j.1460-9568.2006.05235.x.

65. Zhao YD, Ou S, Cheng SY, Xiao Z, He WJ, Zhang JH, Ruan HZ. Dendritic development of hippocampal CA1 pyramidal cells in a neonatal hypoxia-ischemia injury model. J Neurosci Res. 2013; 91: 1165-73. doi: 10.1002/ jnr.23247.
66. Han D, Xu L, Xiao H, Prado Schmidt GC, Shi S. Dizocilpine reduces head diameter of dendritic spines in the hippocampus of adolescent rats. Psychiatry Res. 2013; 210: 351-6. doi: 10.1016/j.psychres.2013.04.025.

67. Hampel H, Prvulovic D, Teipel S, Jessen F, Luckhaus C, Frolich L, Riepe MW, Dodel R, Leyhe T, Bertram L, Hoffmann W, Faltraco F, German Task Force on Alzheimer's D. The future of Alzheimer's disease: the next 10 years. Prog Neurobiol. 2011; 95: 718-28. doi: 10.1016/j.pneurobio.2011.11.008. 